\title{
Intracranial Pressure Elevations During Octanoate Infusion in Rabbits: an Experimental Model of Reye's Syndrome
}

\author{
DORIS A. TRAUNER ${ }^{(1))}$ AND HEATHER ADAMS \\ Departments of Neurosciences and Pediatrics, University of California School of Medicine, La Jolla, California. USA
}

\begin{abstract}
Summary
Continuous intravenous infusion of the short-chain fatty acid octanoate into rabbits results in significant increases in intracranial pressure by 2 hr of infusion. Pressure waves are also observed. Muscular paralysis has a protective effect on intracranial pressure. This study has potential implications for the better understanding and more effective treatment of Reye's syndrome.
\end{abstract}

\section{Speculation}

Intravenous infusion of sodium octanoate in rabbits produces an experimental model of Reye's syndrome, including elevated intracranial pressure. This model will be useful to test new therapeutic modalities for control of intracranial pressure in this disorder.

Reye's syndrome is a metabolic encephalopathy seen primarily in children (7). Its clinical features include coma, seizures, hyperventilation, hyperammonemia and lactic acidosis (4). Increased intracranial pressure (ICP) is a common and often fatal complication (9). The cause of the ICP elevation is not known. Elevated serum concentrations of short-chain fatty acids, including octanoate, are found in patients during the acute illness $(6,11)$. Intravenous infusion of octanoate into rabbits produces an experimental model of Reye's syndrome (11) with coma, hypotonia, seizures, and hyperventilation. Electroencephalographic changes include slowing of background rhythms and intermittent epileptiform discharges. A secondary hyperammonemia and lactic acidemia also develop during octanoate infusion. Because of the similarity between experimental octanoate-induced encephalopathy and the clinical features of Reye's syndrome, we examined the effects of octanoate infusion on ICP in rabbits.

\section{MATERIALS AND METHODS}

\section{ANIMAL PREPARATION}

Two $\mathrm{kg}$ male albino rabbits were anesthetized with ketamine $(50 \mathrm{mg} / \mathrm{kg})$ and pentobarbital $(30 \mathrm{mg} / \mathrm{kg})$ by intraperitoneal injection. The femoral arteries were catheterized with polyethylene tubing and connected to a pressure transducer. Tracheotomies were performed using a No. 4 endotracheal tube connected to a Harvard small animal respirator. The animals were mechanically ventilated using rates and volumes adjusted to maintain arterial $\mathrm{pH}, \mathrm{PO}_{2}$, and $\mathrm{PCO}_{2}$ in the physiologic range. A 23-gauge butterfly needle was inserted into the ear vein, and muscular paralysis was induced and maintained with intravenous pancuronium bromide $(1.0 \mathrm{mg} / \mathrm{hr})$. A small incision was made over the occiput and a 20 gauge intercath inserted into the cisternal space for intracranial pressure recording and connected to a pressure transducer. Needle electrodes were inserted into frontal and occipital scalp regions bilaterally for electroencephalographic recordings. A YSI temper- ature probe was inserted into the rectum for temperature monitoring. Blood pressure, ICP, electroencephalogram, and temperature were recorded continuously on a Beckman R611 eight-channel polygraph.

\section{OCTANOATE INFUSION}

The animals were allowed to stabilize for at least $2 \mathrm{hr}$. Arterial blood gas determinations were performed during the control period and hourly during octanoate infusion. Infusion was begun when the electroencephalogram returned to an awake pattern and when blood pressure and arterial blood gases were in the physiologic range. Sodium octanoate $(\mathrm{pH} 7.4)$ was infused as an 0.1 to 0.2 molar solution at the following rates: $0.78,1.17,1.56$, and 2.28 mmoles/hr. Infusion continued for $6 \mathrm{hr}$ or until the animal died. Control rabbits were given continuous infusions of normal saline at similar rates over 4 to $6 \mathrm{hr}$.

\section{PREPARATION OF OCTANOATE}

Octanoic (caprylic) acid (Sigma Chemical Co., St. Louis, MO) was prepared as a 1 molar solution in normal saline. The solution was titrated to $\mathrm{pH} 11.5$ with $5 \mathrm{~N}$ sodium hydroxide and then back titrated to $\mathrm{pH} 7.4$ with $\mathrm{I} \mathrm{N}$ hydrochloric acid. The resultant solution was clear and free of precipitate or fat droplets and water soluble. The octanoate was diluted to final concentrations of 0.1 to 0.2 molar with normal saline.

Arterial blood gas determinations were performed in the pulmonary function laboratory using an Instrumentation Laboratory model 113 blood gas analyzer.

Data was analyzed for statistical significance using the Student $t$ test (10). A total of 31 rabbits was used, with a minimum of four rabbits in each group tested.

A small group of animals was carried through the experiment at an infusion rate of $2.28 \mathrm{mM} / \mathrm{hr}$ octanoate without muscular paralysis and with spontaneous respirations.

Anesthesia was induced in some animals using ketamine alone at $100 \mathrm{mg} / \mathrm{kg}$; other animals had pentobarbital alone at $50 \mathrm{mg} /$ $\mathrm{kg}$, whereas others received a combination of both. Since no differences were noted between groups of animals given each anesthetic, the results from all types of anesthesia are grouped together.

\section{RESULTS}

ICP elevations rose significantly by 1 to $2 \mathrm{hr}$ after infusion of octanoate began (Fig. 1). Maximal ICP elevations occurred with rates of 1.17 and $1.56 \mathrm{mmoles} / \mathrm{hr}$ (Table 1). At higher rates (2.28 $\mathrm{mM} / \mathrm{hr}$ ), the animals tended to die after 1 to $2 \mathrm{hr}$ of infusion with a rapid rise in intracranial pressure followed by a drop in blood pressure as a terminal event. At lower concentrations, the animals tended to live longer and show a more slowly progressive rise in ICP. At times, pressure waves were observed of the type described as plateau waves (Fig. 2). These waves occurred even in the absence of a sustained increase in ICP. 


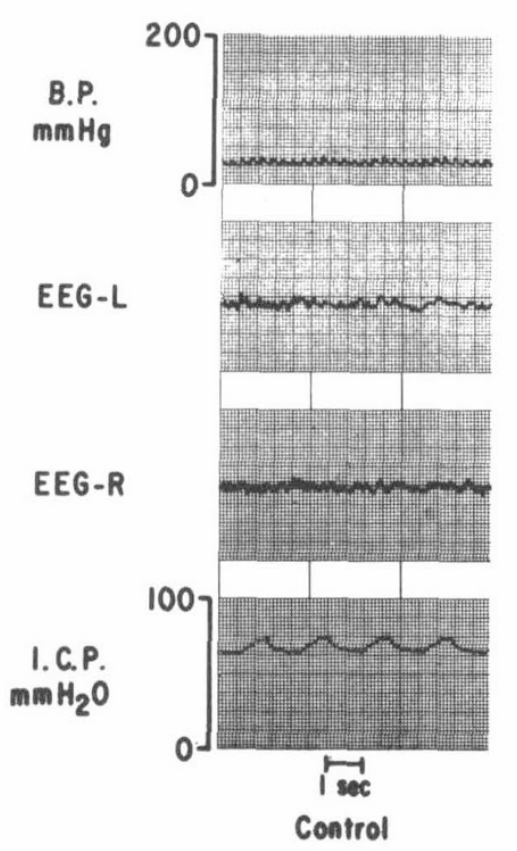

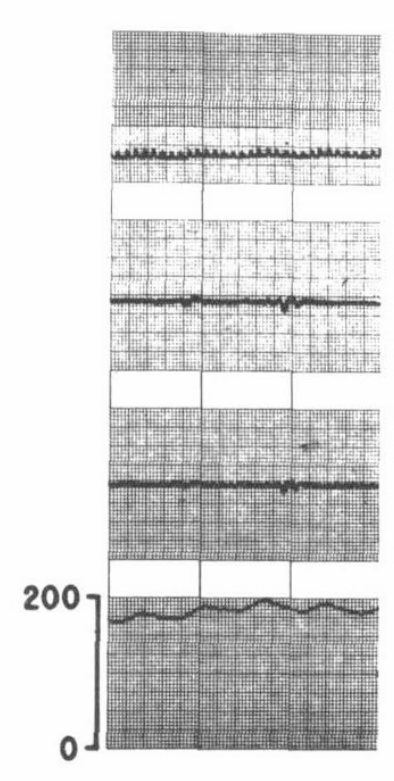

2 Howr Infueion

Fig. I. ICP elevation during octanoate infusion at $1.56 \mathrm{mM} / \mathrm{hr}$. By 2

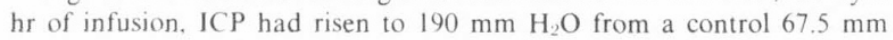
$\mathrm{H}_{2} \mathrm{O}$. Electroencephalogram suppression is apparent. Blood pressure remained stable.

Table 1. ICP during octanoate infusion

\begin{tabular}{lcc}
\hline & $\bar{x}^{\prime}$ & $P$ \\
\hline Control & $41.76 \pm 3.55^{2}$ & \\
$0.78 \mathrm{mM} / \mathrm{hr}$ octanoate & $32.50 \pm 6.69$ & $\mathrm{NS}$ \\
$1.17 \mathrm{mM} / \mathrm{hr}$ octanoate & $107.50 \pm 33.51$ & $<0.001$ \\
$1.56 \mathrm{mM} / \mathrm{hr}$ octanoate & $91.82 \pm 26.42$ & $<0.01$ \\
$2.28 \mathrm{mM} / \mathrm{hr}$ octanoate & $48.50 \pm 6.05$ & $\mathrm{NS}$ \\
\hline
\end{tabular}

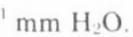

Mean \pm S.E.

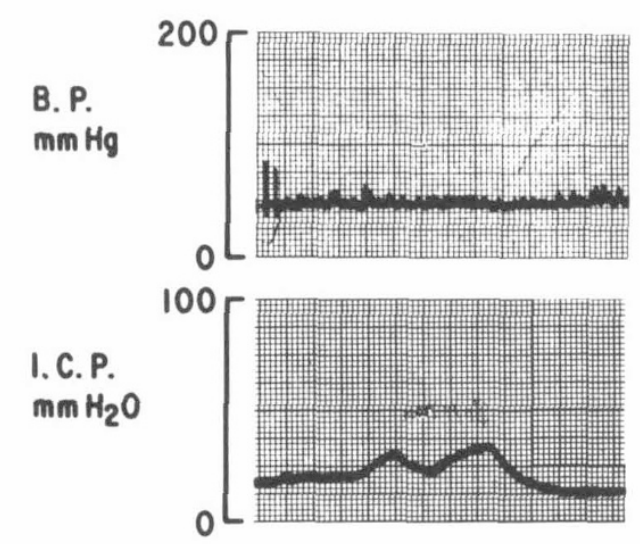

Fig. 2. Pressure waves during infusion of sodium octanoate $2.28 \mathrm{mM}$ / hr. Baseline ICP was not increased at this time.

Muscular paralysis appeared to have a protective effect on intracranial pressure, in that the ICP was significantly higher in nonparalyzed rabbits as compared to paralyzed rabbits given octanoate at $2.28 \mathrm{mM} / \mathrm{hr}$ (Table 2).

No significant changes were noted in $\mathrm{pH}, \mathrm{PO}_{2}$, or $\mathrm{PCO}_{2}$ during the ICP elevations. The only exception was that when ICP elevations occurred as a terminal event, the animals tended to become acidotic and hypoxic. Heart rate showed no significant variation during the course of the infusion. Blood pressure likewise remained stable until late in the infusion when the animals had a blood pressure drop after an acute rise in ICP.

Table 2. Effect of muscular paralysis on ICP during octanoate infusion at $2.28 \mathrm{mM} / \mathrm{hr}$

\begin{tabular}{lcc} 
& $\overline{\mathrm{x}}^{1}$ & $P$ \\
\hline Unparalyzed & $118.36 \pm 28.39^{2}$ & \\
Paralyzed & $48.50 \pm 6.05$ & $<0.05$
\end{tabular}

Controls

$\begin{array}{ll}\text { Unparalyzed } & 46.59 \pm 11.96 \\ \text { Paralyzed } & 41.76 \pm 3.55\end{array}$

NS

mm $\mathrm{H}_{2} \mathrm{O}$.

Mean \pm S.E.

\section{DISCUSSION}

Infusion of the short-chain fatty acid sodium octanoate produces a number of clinical and biochemical abnormalities (11) which are strikingly similar to the problems found in patients with Reye's syndrome. Clinical changes include coma, seizures, and hyperventilation. Biochemical alterations consist of hyperammonemia and lactic acidemia. Thus, octanoate infusion appears to produce an experimental model for Reye's syndrome. The present study documents for the first time that an endogenous toxin found in Reye's syndrome patients has been implicated as a cause of increased intracranial pressure. In a previous report (11), it was shown that during a similar rate of infusion, serum octanoate concentrations were of the same order of magnitude as those found in patients with Reye's syndrome. Therefore, ICP elevations occur at concentrations comparable to those in patients.

Long-chain polyunsaturated fatty acids have been shown to produce brain edema in vitro (2). However, long-chain fatty acids are not elevated in Reye's syndrome (6); thus, the ICP changes found in this disease cannot be explained by the action of polyunsaturated fatty acids.

In addition to sustained elevations of intracranial pressure, plateau waves were also observed frequently. These waves were first described by Lundberg in 1960 (5) in patients with brain tumors and have subsequently been described in connection with increased intracranial pressure secondary to subarachnoid hemorrhage (15) and Reye's syndrome (12). The mechanism underlying development of plateau waves is unclear. Wald and Hochwald (16) suggest that plateau waves are produced when regional cerebral blood flow is compromised. Risberg et al. (8) described an increase in cerebral blood volume during plateau waves and suggested that such waves occur during an intermediate phase in the development of intracranial hypertension in which cerebral autoregulation is attempting to compensate for volume and pressure changes within the brain. Plateau waves disappear as intracranial hypertension becomes severe and decompensation of autoregulatory mechanisms occurs. The fact that plateau waves appeared in our animals before sustained ICP elevations is compatible with this view.

What is the mechanism underlying the increased intracranial pressure found during octanoate infusion? A number of possible causes exist. Several studies have suggested that short-chain fatty acids are toxic to mitochondria. Short-chain fatty acids produce mitochondrial swelling in vitro (17). Ansevin (1) has demonstrated that serum from patients with Reye's syndrome inhibits brain mitochondrial function in vitro and that this inhibition is blocked by the prior addition of fatty-acid-free albumin to the serum. Inhibition of mitochondrial function could explain the development of a cytotoxic form of cerebral edema. Another possible means of producing ICP increases is through an alteration in neuronal or cerebrovascular membranes, either specific or nonspecific. Fatty acids might damage membranes nonspecifically via a detergent effect. However, at least for long-chain fatty acids this appears not to be the cause of cerebral edema formation (2). Fatty acids may alter blood-brain barrier permeability in other ways and produce a vasogenic type of brain edema. Octanoate increases fluorescent diffusion of catecholamines around brain capillaries (13), suggesting an alteration in capillary permeability. The sig- 
nificance of this alteration has yet to be established. Finally, octanoate is capable of inhibiting $\mathrm{Na}^{+} \mathrm{K}^{+}$ATPase activity $(3,14)$. A block in brain oxidative metabolism could also produce a cytotoxic effect. It is also likely that early effects include changes in cerebral blood flow and cerebrovascular volume. Further studies are needed to clarify the effects of short-chain fatty acids on these functions.

Whatever the cause of the ICP increase, it is clear that octanoate is deleterious to normal cerebral function. Methods aimed at reducing circulating short-chain fatty acid concentrations in diseases such as Reye's syndrome may lead to more effective control of intracranial pressure and a better outcome. We have also demonstrated a protective effect on ICP of muscular paralysis with pancuronium bromide and suggest that this agent may be a useful adjunct to therapy in severe Reye's syndrome.

\section{REFERENCES AND NOTES}

1. Ansevin, C. F.: Reye's syndrome: serum-induced alterations in brain mitochondrial function are blocked by fatty acid-free albumin. Neurology, 30: 160 (1980).

2. Chan. P. H., and Fishman, R. A.: Brain edema: induction in cortical slices by polyunsaturated fatty acids. Science (Wash. D. C.), 201: 358 (1978).

3. Dahl. D. R.: Short-chain fatty acid inhibition of rat brain $\mathrm{Na}^{+}-\mathrm{K}^{+}$adenosine triphosphosphatase. J. Neurochem., 15: 815 (1968).

4. Huttenlocher, P. R., and Trauner. D. A.: Reye's syndrome. In: P. J. Vinken. G. W. Bruyn: Handbook of Clinical Neurology. Vol. 29, pp. 331-344, (North Holland Publishing Co., Amsterdam. 1977).

5. Lundberg. $\mathrm{N}_{\text {.: }}$ Continuous recording and control of ventricular fluid pressure in neurosurgical practice. Acta Psychiatr. Scand., 36 (Suppl. 149): I (1960).

6. Mamunes. P.. DeVries, C. H.. Miller, C. D.. and David, R. B.: Fatty acid quantitations in Reye's syndrome. In: J. D. Pollack: Reye's Syndrome. pp. 245-254 (Grune \& Stratton Inc., New York, 1975).

7. Reye, R. D. C., Morgan. G.. and Baral. J.: Encephalopathy and fatty degeneration of the viscera. Lancet, 2: 749 (1963)

8. Risberg, J.. Lundberg. N., and Ingvar. D. H.: Regional cerebral blood volume during acute transient rises of the intracranial pressure (plateau waves). J. Neurosurg.. 31: 303 (1969).

9. Shaywitz. B. A., Leventhal. J. M., Kramer. M. A.. and Venes, J. L.: Prolonged continuous recording of intracranial pressure in severe Reye's syndrome. Pediatrics, 59: 595 (1977).

10. Steele. R. G. D.. and Torrie, J. H.: Principles and procedures of statistics. p. 57 (McGraw-Hill Book Co. Inc., New York. 1960).

11. Trauner, D. A., and Huttenlocher, P. R.: Short-chain fatty acid-induced central hyperventilation in rabbits. Neurology, 28: 940 (1978).

12. Trauner, D. A.. Brown. R. E., Ganz, E.. and Huttenlocher: P. R.: Treatment of increased intracranial pressure in Reye's syndrome. Ann. Neurol.. 4: 275 (1978).

13. Trauner, D. A.. and DeLaTorre. J.: Effects of sodium octanoate on blood-brain barrier permeability. Soc. Neurosci. Abs., 3: 147 (1979),

14. Trauner. D. A.: Regional cerebral $\mathrm{Na}^{+} \mathrm{K}^{+}$ATPase activity following octanoate administration. Pediatr. Res.. 14:844 (1980).

15. Troupp. H., and DeRougemont, J.: Chairmen's comments. In N. Lundberg. U. Ponten. M. Brock: Intracranial pressure. pp. 419- 20 (Springer Verlag. New York. (975).

16. Wald. A. and Hochwald. G. M.: An animal model for the production of intracranial pressure plateau waves. Ann. Neurol., l: 486 (1977).

17. Zborowski, U., and Wojtczak, L.: Induction of swelling of liver mitochondria by fatty acids of various chain length. Biochem. Biophys. Acta, 70: 596 (1913).

18. Requests for reprints should be addressed to: D. A. Trauner, M.D., University Hospital. H-815, San Diego, CA 92103 (USA).

19. This research was supported by Basic Research Grant 1-699 from March of Dimes Birth Defects Foundation and by the National Reye's Syndrome Foundation of Bryan. Ohio.

20. Received for publication October 15, 1980.

21. Accepted for publication December 12. 1980. 